\title{
Maternal and Paternal Depression During Pregnancy in China: Prevalence, Correlates, and Network Analysis [Corrigendum]
}

Zhang Y, Sun H, Li W, et al. Neuropsychiatr Dis Treat. 2021;17:2269-2280.

The authors have advised the affiliation list on page 2269 is incorrect. The correct author list and affiliations are as follows.

Yongfu Zhang
Hengwen Sun
We*
Wengao $\mathrm{Li}^{3}$
Xian $\mathrm{Luo}^{4}$
Ting $\mathrm{Liu}^{4}$
Fan Fang
Julan Xiao
Samradhvi Garg

\author{
Yuan Yang ${ }^{4,7,8}$ \\ Yu Chen ${ }^{5}$
}

'Department of Anesthesiology, Guangzhou Women and Children's Medical Centre, Guangzhou, Guangdong, People's Republic of China; ${ }^{2}$ Department of Radiotherapy, Cancer Center, Guangdong Provincial People's Hospital (Guangdong Academy of Medical Sciences), Guangzhou, Guangdong, People's Republic of China; ${ }^{3}$ Department of Psychiatry, 999 Brain Hospital, Guangzhou, Guangdong, People's Republic of China; ${ }^{4}$ Department of Psychiatry, Southern Medical University Nanfang Hospital, Guangzhou, Guangdong, People's Republic of China; ${ }^{5}$ School of Nursing, Southern Medical University, Guangzhou, Guangdong, People's Republic of China; 'School of Health in Social Science, University of Edinburgh, Edinburgh, Scotland, UK; ${ }^{7}$ Unit of Psychiatry, Institute of Translational Medicine, Faculty of Health Sciences, University of Macau, Macau, SAR, People's Republic of China; ${ }^{8}$ Center for Cognition and Brain Sciences, University of Macau, Macau, SAR, People's Republic of China

*These authors contributed equally to this work
Neuropsychiatric Disease and Treatment

\section{Publish your work in this journal}

Neuropsychiatric Disease and Treatment is an international, peerreviewed journal of clinical therapeutics and pharmacology focusing on concise rapid reporting of clinical or pre-clinical studies on a range of neuropsychiatric and neurological disorders. This journal is indexed on PubMed Central, the 'PsycINFO' database and CAS, and is the official journal of The International Neuropsychiatric Association (INA). The manuscript management system is completely online and includes a very quick and fair peer-review system, which is all easy to use. Visit http://www.dovepress.com/testimonials.php to read real quotes from published authors. 